\title{
Designation of Neotype Strains for Micromonospora coerulea Jensen 1932 and Micromonospora chalcea (Foulerton 1905) Ørskov 1923
}

\author{
GEORGE M. LUEDEMANN
}

Microbiology Division, Schering Corporation, Bloomfield, New Jersey 07003

\begin{abstract}
ATCC 27008 and ATCC 12452 are designated as neotype strains for Micromonospora coerulea Jensen 1932 and Micromonospora chalcea (Foulerton 1905) Ørskov 1923, respectively. The data of earlier workers who studied these organisms are discussed, and additional characteristics considered useful for the identification of these species are presented.
\end{abstract}

Neotype strains are designated for Micromonospora coerulea Jensen and Micromonospora chalcea (Foulerton) $\emptyset$ rskov because none of the strains on which the original descriptions of these organisms were based appears to be extant.

\section{MATERIALS AND METHODS}

The strains studied are identified in the discussion and description which follow. Methods used were previously described (14).

\section{DISCUSSION}

Micromonospora coerulea Jensen 1932. Jensen (7) described three new species of Micromonospora from a study of 67 micromonosporae which he had isolated from Australian soils. The species were based primarily on color of the vegetative mycelium ( $M$. coerulea), diffusible pigment (M. fusca, see reference 14), and sparse to poor growth $(M$. parva). Kriss (10) did not consider these criteria to be relevant for speciation, based on his own work with a small number of micromonosporae isolated from soil. I would normally agree with the opinion of Kriss concerning the use of pigment production and strain vigor as criteria for speciation. However, in the case of $M$. coerulea, the dusky blue-green color of Ridgway (18) is quite unusual for a microorganism, and, in studies of many soil micromonosporae, only a small number of these atypically pigmented organisms have been encountered. I have detected only three soil isolates of this color, and their morphological and physiological characters agree with most of those noted by Jensen (7), who isolated only two of these blue-green strains.
Micromonospora coerulea was listed as a synonym of Micromonospora (Thermoactinomyces) vulgaris by Waksman et al. (21); fortunately, this synonymy was not perpetuated by Waksman (Bergey's Manual of Determinative Bacteriology, 7 th ed., p. 744-825).

Sveshnikova et al. (19) described several new species of Micromonospora and cited what appear to be reference strains for a number of other micromonosporae. Among the latter are $M$. chalcea and $M$. coerulea. It is not clear what these authors intended when they listed under $M$. chalcea "type strain 12452 ATCC" and under $M$. coerulea "type strain 510 INA" [see definition of type strain $(3,4,11)]$, for no evidence is presented to show that either of these strains was used in preparing the original descriptions of these organisms. In fact, from the information available, both of these strains appear to have been isolated subsequent to the publication of the original descriptions of these organisms.

Description of the neotype strain (no. 36; ATCC 27008) of Micromonospora coerulea Jensen 1932. Colonies in shaken broth culture are usually composed of long, loosely woven hyphae (open web type) with spores often borne singly on short or long sporophores (Fig. 1 , a-f). The mycelium is 0.4 to $0.6 \mu \mathrm{m}$ in diameter. The spores are spherical, smooth walled by phase-contrast microscopy, and are 0.8 to $1.5 \mu \mathrm{m}$ in diameter. Mycelium rarely fragments except in old cultures. Growth on glucose asparagine agar or starch casein agar is fair to poor. Colonies are of a granular texture, small, and often glossy. The color of the colonies is dark jade green [g2 $1 \mathrm{ni}(2,20)]$. According to the Inter-Society Color CouncilNational Bureau of Standards (8), this color is 

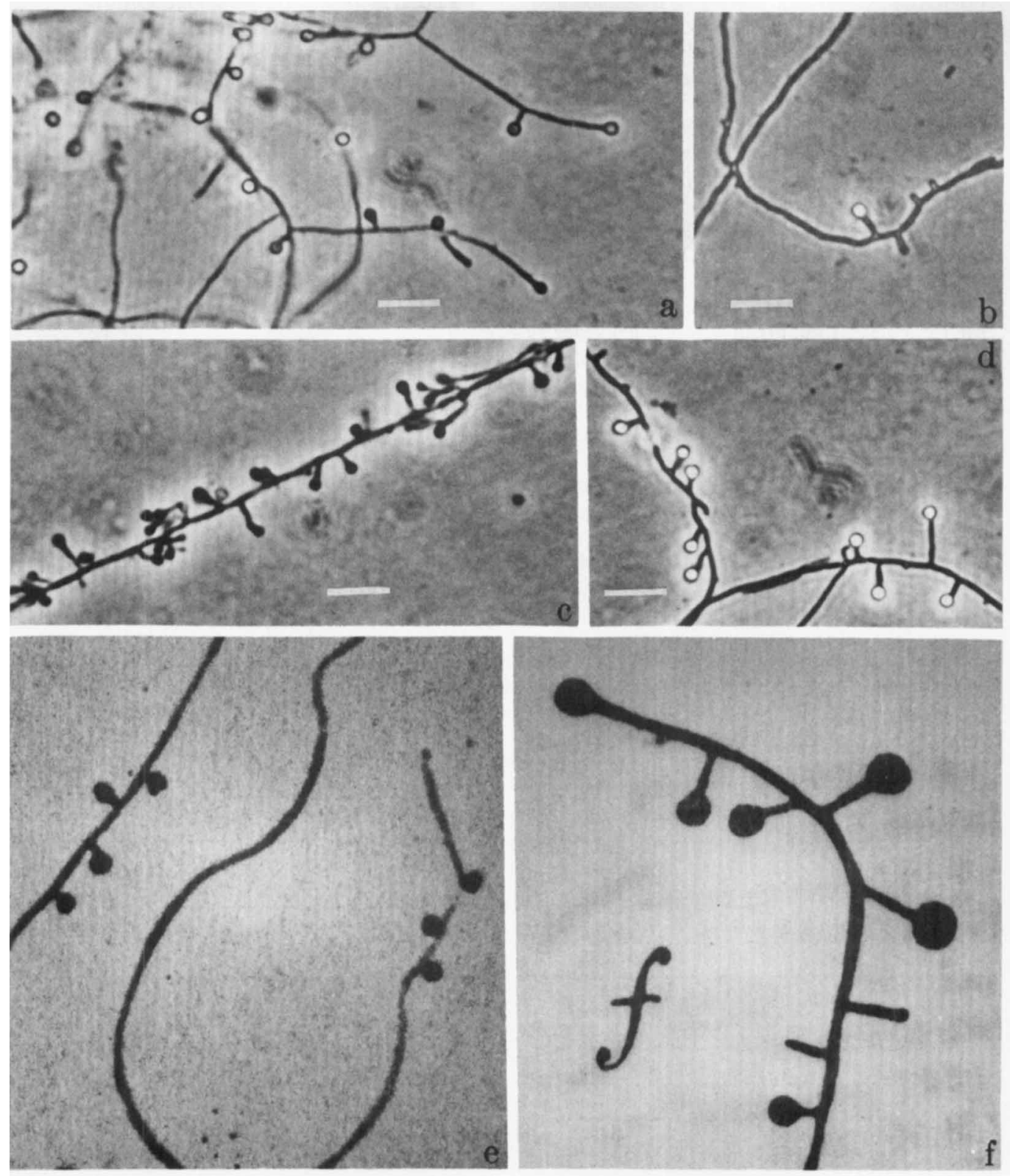

Fig. 1. Micromonospora coerulea $a$ and $c$, Strain no. $36(=A T C C 27008)$, the designated neotype for $M$. coerulea. $b$ and $d$, Strain no. 981 (= ATCC 27082), a strain of $M$. coerulea. $e$, Enlarged photographic reproduction of strain $176 \mathrm{IV}$ by Jensen (6), 18-day filter paper asparagine solution culture; considered by Jensen (7) to be a strain of $M$. coerulea. $f$, Enlarged photographic reproduction of $M$. coerulea by Jensen (7); simple monopodial branching system. a-d. The marker represents $10 \mu \mathrm{m}$. 
equivalent to the designation dark bluish green 165 , which is equivalent to the Ridgway 1912 designation dusky green blue, the color originally designated for $M$. coerulea by Jensen (7). No diffusible pigment or aerial mycelium is produced. Growth on $1 \%$ yeast extract-1\% glucose agar is good; the texture is granular, and the color of the periphery of the colony is amber (g3lc), whereas the center of the colony is dark green (g21 pl). Growth on Bennett's agar is good, plicate, and dark olive green (g24 1/2 pn). Growth on Emerson's agar is fair, granular, and dark green (g24pn). Growth on agar media is often slow, requiring three to five weeks to develop. Growth is initially a pale yellow orange turning to a yellow green and finally a dark blue green or greenish black. The blue-green mycelial pigment is water-soluble and is an acid-base indicator, being green in the basic range and a blue gray and precipitated in the acid range. Carbohydrate utilization patterns are given in Table 1. Maximum sodiumchloride tolerance, $1.5 \%$. Grows well on potato plug without the addition of $\mathrm{CaCO}_{3}$. Hydrolyzes starch. Hydrolysis of gelatin is poor. Growth on milk agar is fair; hydrolysis is restricted, requiring three to five weeks before a small zone of clearing occurs around the colony. Cellulose strips are decomposed very slowly, if at all; colonies above the liquid level of the cellulose are blue-green, whereas below the liquid level the colonies are a pale yellow orange. Nitrate not reduced to nitrite. Source: isolated by the author from a soil sample from the top of Mt. Haleakala, Island of Maui, Hawaiian Islands.

Two other strains of this species have been isolated which produce a greenish blue pigment similar to that produced by the neotype strain. Strain 37 (= ATCC 27081) was isolated from a soil sample from Israel and grows poorly on most organic media, perhaps a little better on inorganic nitrogen salts media; it bears a resemblance to the description of Micromonospora bicolor Krasil'nikov 1941. Strain 981 (= ATCC 27082) was isolated from a soil sample from Mexico. This strain grows well on most media and differs in its carbohydrate utilization pattern from that of strain 36 (Table 1). Strain 981 might be considered as belonging to a subspecies or a biotype of $M$. coerulea. "Carbohydrate patterns should be treated with a degree of flexibility in order to attain an understanding of strain latitude and overall grouping value of the method. Strains of a species that have evolved in different geographic localities may of necessity have had to develop a different 'bag' of enzymes in order to utilize locally available substrates; what remains of a common utilization pattern among geographically diverse strains of a species should have species group recognition value" (13).

Micromonospora chalcea (Foulerton 1905) Orskov 1923. The description by Foulerton of Streptothrix chalcea (5) consists of a report made before the Pathological Society of London and recorded in The Lancet in one

TABLE 1. Carbohydrate utilization by strains of Micromonospora coerulea

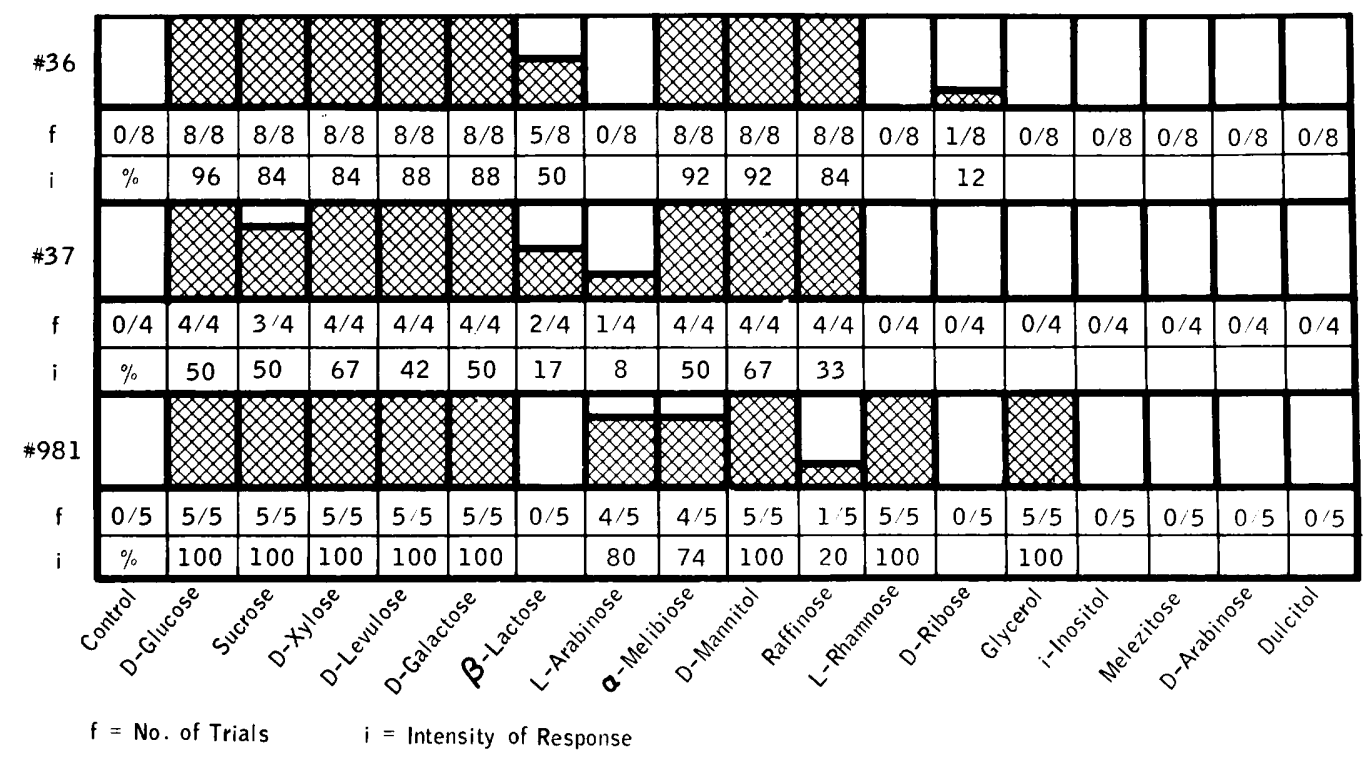


short paragraph. A key characteristic appeared to be colony color, which on nutrient agar was copper, becoming a deep reddish brown with age; growth on potato was deep red in color. Gelatin was slowly liquefied, and milk precipitated and gradually cleared. Starch was hydrolyzed. Growth occurred on ordinary culture media and was somewhat better at $37 \mathrm{C}$ than at $22 \mathrm{C}$. The thermal death point was recorded as between 60 and $70 \mathrm{C}$. The organism was isolated from the air. No information on morphology was given.

$\emptyset$ rskov (17) obtained a strain of $S$. chalcea from Kral's Bakteriologisches Museum in Vienna. Based on a detailed study of the morphology of $S$. chalcea, Ørskov placed this strain in his group III, for which he proposed the generic name Micromonospora because of this organism's unique micromorphology and absence of aerial mycelium.

Jensen (7) studied S. chalcea from Pribram's Mikrobiologische Sammlung (formerly Kral's Bakteriologisches Museum, Vienna) and commented: "The present strain of $S$. chalceae (sic) appeared to have undergone such profound changes during the long period of artificial cultivation, that it showed hardly any resemblance to the earlier descriptions.... As this organism thus seems, since its examination in 1923 by $\emptyset$ rskov, to have lost the very character which its identification first and foremost rests, viz., the spore formation, it cannot be identified directly with any of the other strains of Micromonospora." This appears to have been the fate of the strain of the type species of the genus Micromonospora. Jensen believed that 60 of 67 strains of Micromonospora that he had isolated from the soil belonged to one large species identified as Micromonospora chalcea and characterized by spore formation, red vegetative mycelium without any aerial growth, and a comparatively strong proteolytic action.

Lumping these 60 isolates into one species has certain aspects which are commendable. My own observations of numerous soil isolates tend to confirm Jensen's lumping, particularly if one considers his summary description of $M$. chalcea as: "Vegetative mycelium on dextroseasparagine-agar, heavy, compact, raised, not spreading much into the medium. Spore-layer well developed, moist and glistening, brownishblack to greenish-black, this colour sometimes spreading through the whole mass of growth. Grows in liquid media as small firm orange granules or flakes. Starch is hydrolyzed. Gelatin is liquefied. Milk is digested with a faintly acid reaction, mostly after a previous coagulation. Many strains invert saccharose. Some strains reduce nitrate to nitrite. Most strains decompose cellulose. Proteolytic action seems

TABLE 2. Carbohydrate utilization by strains of Micromonospora chalcea

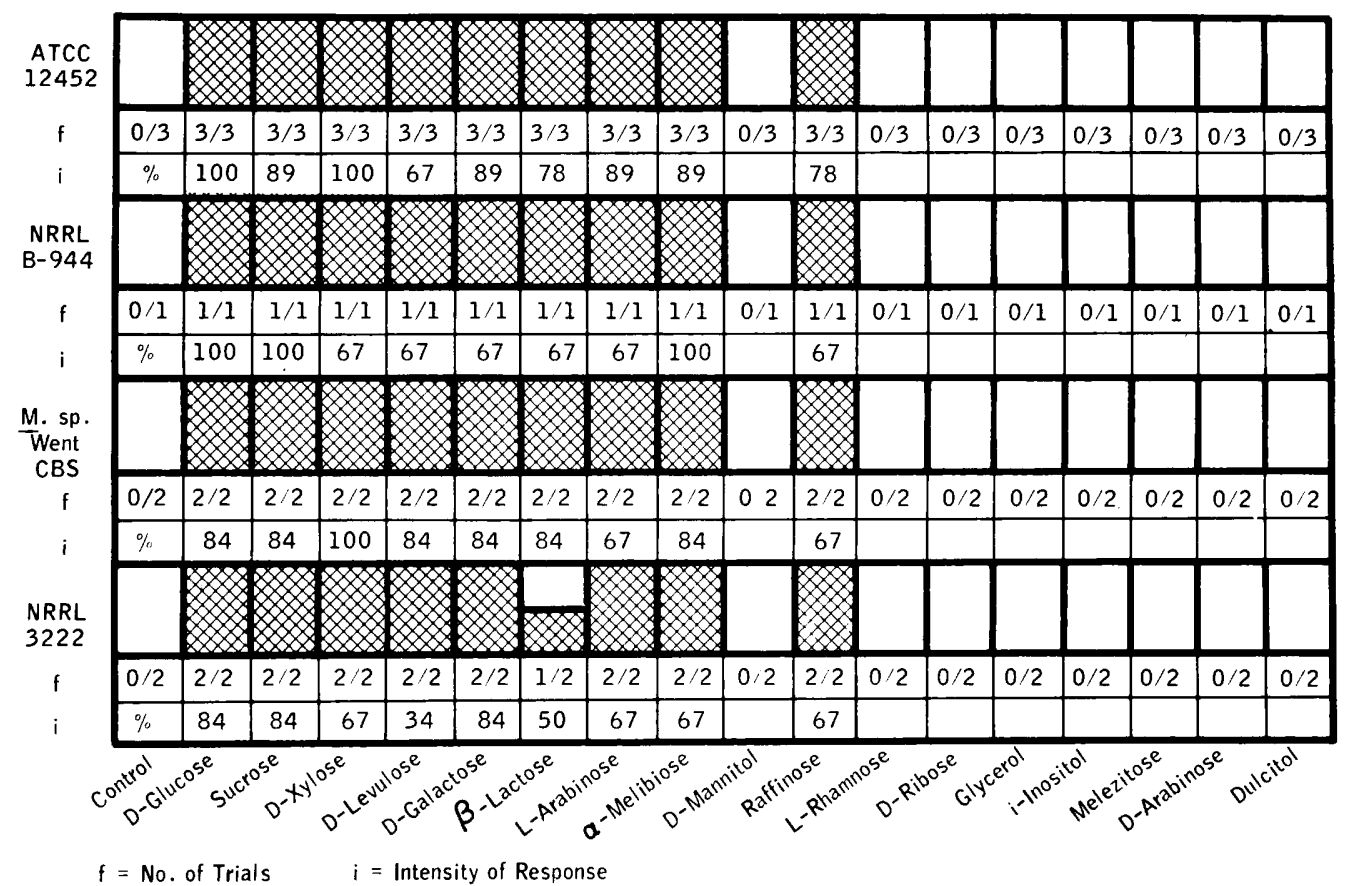



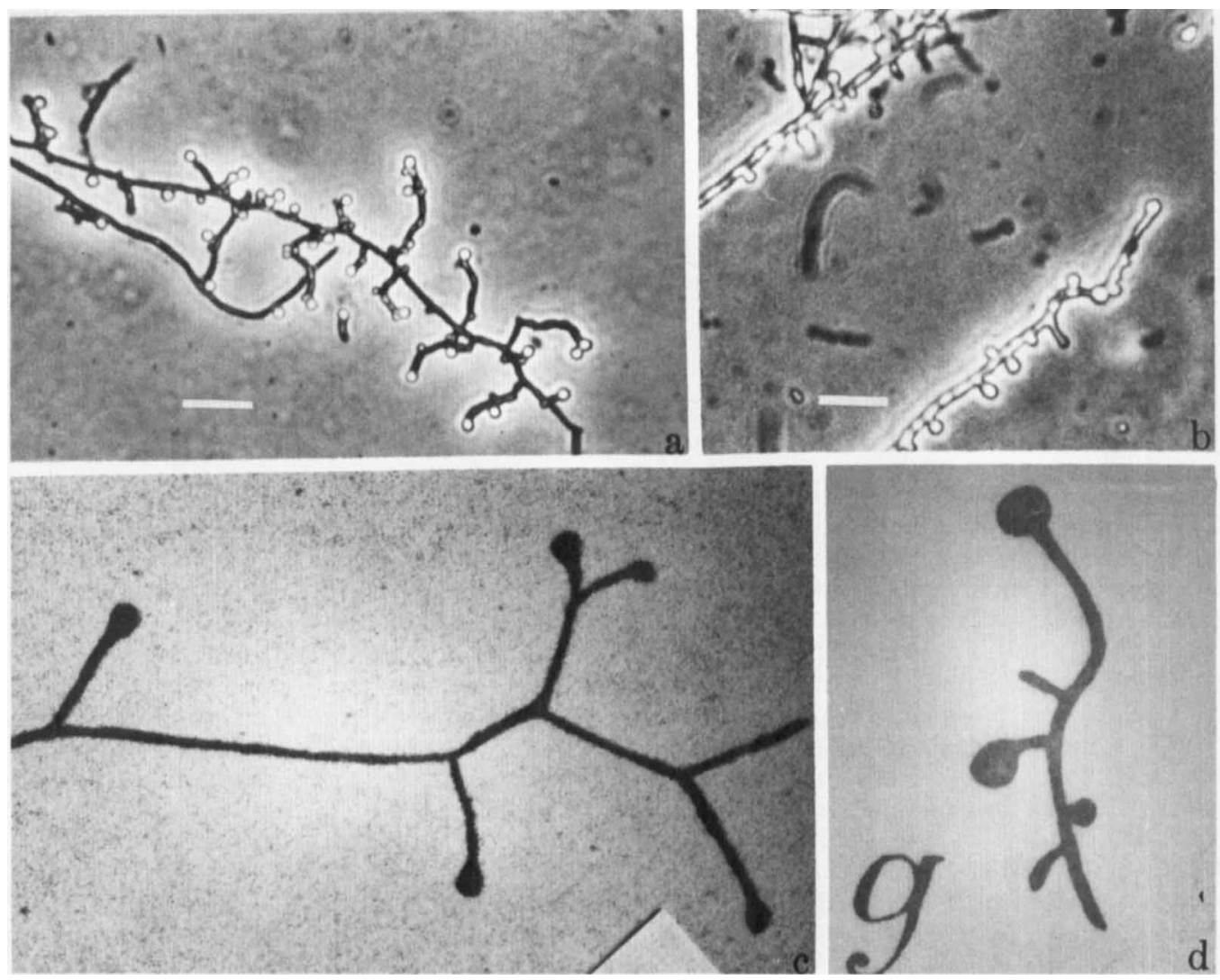

Fig. 2. Micromonospora chalcea. a, M. chalcea NRRL B-944 (= ATCC 27083), showing a monopodial branching system. $b, M$. chalcea ATCC 12452, the neotype strain, showing sessile spores. $c$, Enlarged photographic reproduction of strain 176 XVII by Jensen (6), showing monopodial and pseudodichotomous branching systems; considered by Jensen (7) to be a strain of M. chalcea. d, Enlarged photographic reproduction of $M$. chalcea by Jensen (7), showing a simple monopodial branching system; grown in glucose asparagine solution for 6 days at $32 C$. $a$ and $b$, The marker represents $10 \mu \mathrm{m}$.

stronger in this than in the other species of this genus. Optimum temperature for growth, $30-35^{\circ} \mathrm{C}$. Thermal death point of mycelium, $70^{\circ} \mathrm{C}$ in $2-5$ minutes. Spores resist $80^{\circ} \mathrm{C}$ for 1-5 minutes."

Description of the neotype strain (ATCC 12452) of Micromonospora chalcea (Foulerton 1905) Orskov 1923. The strain here designated as the neotype of $M$. chalcea is ATCC 12452, which is cited in U.S. Patent 2,809,919. 1957. This strain has been chosen because it produces a pigment closely resembling the copper to deep reddish brown colony color mentioned by Foulerton (5) and the deep cinnabar red of Drskov (17). The color of this strain also appears to agree with the brownish black colony color produced early on water agar as noted by $\emptyset$ rskov (17). The physiological properties of this strain agree with those described by Foulerton (5). Previously, descriptive data were given on this strain by Luedemann and Brodsky $(15,16)$.

Other strains studied and believed to be identifiable with $M$. chalcea are NRRL B-944 (= ATCC 27083), NRRL 3222 (= ATCC 27084) identified as $M$. chalcea subsp. flavida Weinstein et al. (U.S. Patent 3,454,696. 1968), and the Micromonospora sp. deposited by Went at the CBS.

Micromonospora sp. ATCC 10026 has also been identified as $M$. chalcea (U.S. Patent 2,809,919. 1957); however, I believe this strain has a greater affinity to $M$. narashinoensis (12, $13,15)$.

Data useful in recognizing strains of $M$. chalcea include: carbohydrate-utilization patterns (Table 2 ); maximum sodium chloride tolerance, 4 to $5 \%$; good growth on acid or 
$\mathrm{CaCO}_{3}$-neutralized potato plugs; and strong proteolytic action on milk agar. Sporulating hyphae of strains identified as $M$. chalcea may be compared in Fig. 2. Colonies in shaken broth cultures are of the open web type (13).

\section{LITERATURE CITED}

1. Buchanan, R. E. 1964. Proposal for emendation of rule 9d. Definition of neotype strain and method of designation. Int. Bull. Bacteriol. Nomencl. Taxon. 14:169-171.

2. Color harmony manual, 4 th ed. 1958. Container Corp. of America, Chicago.

3. Cowan, S. T. 1968. A dictionary of microbial taxonomic usage. Oliver and Boyd, Edinburgh.

4. Editorial Board of the Judicial Commission of the International Committee of Nomenclature of Bacteria. 1966. International code of nomenclature of bacteria. Int. J. Syst. Bacteriol. 16:459-490.

5. Foulerton, A. G. R. 1905. New species of Streptothrix isolated from the air. Lancet 1:1199-1200.

6. Jensen, H. L. 1930. The genus Micromonospora Ørskov, a little known group of soil microorganisms. Proc. Linnean Soc. N.S.W. 55:231-249.

7. Jensen, H. L. 1932. Contributions to our knowledge of the Actinomycetales. III. Further observations on the genus Micromonospora. Proc. Linnean Soc. N.S.W. 57:173-180.

8. Kelly, K. L., and D. B. Judd. 1955. The ISCC-NBS method of designating colors and a dictionary of color names. Nat. Bur. Stand. Circ. 553, 1 Nov. 1955. U.S. Gov. Printing Off., Washington, D.C.

9. Krasil'nikov, N. A. 1941. Keys to Actinomycetales. Izdatel'stvo Akademii Nauk SSSR MoskvaLeningrad (English translation, S. Nemchonok 1966, U.S. Dept. of Commerce, Clearing House for Federal Scientific and Technical Information, Springfield, Va.
10. Kriss, A. E. 1939. The micromonospore-an actinomycete-like organism. (Micromonospora globosa n.sp.) Mikrobiologiy a 8:178-185.

11. Lessel, E. F. 1970. Progress and problems in bacterial systematics. Int. J. Syst. Bacteriol. 20:339-344.

12. Luedemann, G. M. 1969. Micromonospora taxonomy, p. 101-133. In D. Perlman (ed.), Advances in Applied Microbiology, vol. 11 . Academic Press Inc., New York.

13. Luedemann, G. M. 1971. Species concepts and criteria in the genus Micromonospora. Trans. N.Y. Acad. Sci. 33:207-218.

14. Luedemann, G. M. 1971. Micromonospora purpureochromogenes (Waksman and Curtis 1916) comb. nov. (Subjective synonym: Micromonospora fusca Jensen 1932.) Int. J. Syst. Bacteriol. $21: 240-247$.

15. Luedemann, G. M., and B. C. Brodsky. 1964. Taxonomy of gentamicin-producing Micromonospora. Antimicrob. Ag. Chemother.-1963, p. 116-124.

16. Luedemann, G. M., and B. C. Brodsky. 1965. Micromonospora carbonacea sp. $\mathrm{n}$., an everninomicin-producing organism. Antimicrob. Ag. Chemotherapy-1964, p. 47-52.

17. Orskov, J. 1923. Investigation into the morphology of the ray fungi. Levin and Munksgaard, Copenhagen.

18. Ridgway, R. 1912. Color standards and color nomenclature. Washington, D.C.

19. Sveshnikova, M. A., T. S. Maksimova, and E. S. Kudrina. 1969. The species of the genus

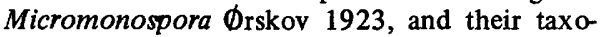
nomy. Mikrobiologiya 38:883-893. (English translation, p. 754-763).

20. Taylor, H. D., L. Knoche, and W. C. Granville. 1950. Descriptive color names dictionary. Container Corp. of America, Chicago.

21. Waksman, S. A., W. W. Umbreit, and T. C. Cordon. 1939. Thermophilic actinomycetes and fungi in soils and in composts. Soil Sci. 47:37-61. 